\title{
Policy Implementation Framework and Family-Friendly Work Policy: Evidence from Flex-Working Programs in South Korea's Public Sectors
}

\author{
Yongjin $\mathrm{Sa}^{1}$ \\ ${ }^{1}$ School of Public and International Affairs, University of Baltimore, Baltimore, MD, USA \\ Correspondence: Yongjin Sa, School of Public and International Affairs, University of Baltimore, Baltimore, MD, \\ USA. E-mail: yongjinsa@gmail.com
}

Received: July 3, 2013 Accepted: August 24, 2013 Online Published: October 29, 2013

doi:10.5539/ass.v9n15p189 URL: http://dx.doi.org/ass.v9n15p189

\begin{abstract}
The main purpose of this study is to explore factors (e.g., political, organizational, cultural \& institutional) that negatively influence the implementation of flex-working programs (i.e., flex-time, part-time and at-home work programs) and thus result in only a very small number of government employees (1.6 percent in 2011) taking advantage of these programs in South Korea's public organizations. To address, this research uses Mazmanian \& Sabatier's (1989) conceptual framework of the implementation process including three groups of independent variables (e.g., the tractability of the problem(s) being addressed, the ability of the statute to structure favorably the implementation process and the net effect of a variety of political variables on the balance of support for statutory objectives) which exert an influence on the implementation process. Finally, to successfully implement flex-working programs in Korea's public sector and to attain their primary policy goal of improving an employee's work/life balance, this research concludes with the three suggestions on policy contents and managerial leadership.
\end{abstract}

Keywords: flex-working programs, family-friendly work policy, policy implementation framework, policy evaluation

\section{Introduction}

Over the past two decades, the rates of women's economic activity and participation have consistently increased in both Korea's private and public workforces. In particular, the number of female government employees has increased remarkably, as shown in Table 1.

Table 1. Number of female government employees by year (1998-2008) (combined number of civil servants in executive/legislative/judicial branch)

\begin{tabular}{lllllll}
\hline & 1998 & 2000 & 2002 & 2004 & 2006 & 2008 \\
\hline Total & 888,217 & 849,152 & 869,030 & 915,689 & 940,397 & 968,836 \\
Female & 263,853 & 267,647 & 286,074 & 324,576 & 365,178 & 395,464 \\
Percent & 29.7 & 31.5 & 32.9 & 35.4 & 38.8 & 40.8 \\
\hline
\end{tabular}

Source: The Ministry of Public Administration and Security (MOPAS)

As female economic activity rates increase in Korea, work-family conflicts are becoming significant social and labor market challenges. Specifically, married career women who perform economic activities and simultaneously take care of their families and children suffer from very high levels of job stress, as well as mental and physical pain. In addition, as the Korean society ages, a number of female economic activities should be increased to support both their parents and children (Jang \& Choi, 2009). Another problem, as shown in Table 2 , is that the rate of female employment in the Senior Civil Service (SCS) (i.e., high-profile public officials) has not increased proportionately to the increased rate of female economic activities in Korean public organizations. 
Table 2. Number of female SCS civil servants in executive/legislative/judicial branch in 2011

\begin{tabular}{llllllllllllll}
\hline & Total & & \multicolumn{9}{c}{ Executive Branch } & \multicolumn{5}{c}{ Legislative Branch } & \multicolumn{3}{c}{ Judicial Branch } \\
\hline & Total & Female & $\%$ & Total & Female & $\%$ & Total & Femal & e & Total & Femal & $\%$ \\
Tota & 989,13 & 413,24 & 41. & 965,03 & 404,80 & 41. & 4,09 & 1,428 & 34 & 16,90 & 6,024 & 35. \\
1 & 8 & 8 & 8 & 5 & 8 & 9 & 6 & 9 & 0 & 6 \\
SCS & 1,032 & 40 & 3.9 & 1,032 & 40 & 3.9 & 0 & 0 & 0 & 0 & 0 & 0 \\
\hline
\end{tabular}

Source: The Ministry of Public Administration and Security (MOPAS)

Heavy burdens of household chores and child care weigh especially on female employees; long working hours, inflexible work environments, and an imbalance between work and family are among the reasons that lead to only a very small number of female employees filling high-ranking positions in public sectors (Jang \& Choi, 2009; Jin \& Chang, 2010). Therefore, the Korean government will face economic and social harm due to the loss of competent female employees, as well as intensifying family and social conflicts if these work-family conflicts are not addressed to improve the balance between work and family.

In addition, employees' needs and values for self-development activities (e.g., education to obtain advanced degrees, learning foreign languages, and physical exercise) and numerous types of leisure have consistently increased in both the public and private workforce. As a result, government employees are likely to prefer flex-working schedules rather than traditional work styles (i.e., 9-5 work days, Monday-Friday work weeks, or on-site work) to spend more of their time in self-development and leisure activities (Jang \& Choi, 2009; Jin \& Chang, 2010).

To address these problems and policy needs, two departments of the central government of Korea-the Ministry of Public Administration and Security (MOPAS) and the Ministry of Employment and Labor (MOEL)-formulated and implemented three types of flex-working programs (part-time work, flex-time work, and at-home work) as part of a system of family-friendly employment policies constructed and designed to support employees' work/life balance through the provision of benefits, incentives, subsidies, flexible work schedules, etc. (MOPAS, 2013). Initially, MOPAS and MOEL formulated nine types of flex-working programs-compressed work, part-time work, discretionary work, core-time work, free-dress code, work from home, telework, flex-time, and alternative work schedules-depending on the workplace, hours, working style, dress and type (MOPAS \& MOEL, 2013). This study primarily focuses on three types of the flex-working programs (flex-time, part-time and working from home), which have been used and implemented more often by Korean governments than the other types of flex-working programs in Korean governments. Since 2010, the programs have been implemented at all levels of the Korean government (i.e., central, provincial \& local) (MOPAS \& MOEL, 2013).

Currently, several years after the implementation of flex-working programs in the Korean public sector, only $1.6 \%$ of government employees on average (i.e., 23,609 employees or $3.8 \%$ of all 621,313 central and provincial government employees, and 1,031 employees or $0.3 \%$ of the total 343,722 local government employees) have experience using one of the three largest flex-working programs in 2011 (MOPAS, 2013). Despite low rates of utilization, many government employees perceive the implementation of flex-working programs as important and necessary to achieve a work/family balance (Jang \& Choi, 2009). The main purpose of this study is to explore and identify factors (e.g., political, organizational, cultural and institutional) that negatively influence the implementation of flex-working programs and thus result in only a very small number of government employees taking advantage of these programs.

This paper is organized as follows. First, a literature review describes the flex-working programs and policy implementation frameworks. Next, the contents of the policies and background relevant to the flex-working programs are discussed, as well as the purposes, expected positive and negative outcomes, and the proponents and opponents of implementing the flex-working programs. Finally, the findings are presented based on the implementation framework and are discussed along with the potential evaluation criteria for the flex-working programs. 


\section{Literature Review}

\subsection{Literature on Flex-Working Programs}

Newman \& Mathews (1999, p. 35) note that family-friendly policies are essential to the improvement of women's balance between their personal lives and their career development. The following are representative family-friendly policies implemented in public sectors: alternative work schedules, flex-time, telework or working from home, compressed work schedules, part-time employment, dependent care subsidies or programs, child or family care support, and paid leave for family responsibilities (Lee \& Hong, 2011; Cayer, 2003; Newman \& Mathews, 1999). One of the family-friendly policies, flex-working programs (i.e., alternative work arrangements), has been implemented in both public and private organizations to reduce work-life conflict and to maintain a balance between work and family (Julien, Somerville \& Culp, 2011; Lee \& Hong, 2011; Jang \& Choi, 2009; Jin \& Chang, 2010). Julien et al. (2011, p. 170) state that the primary purpose of alternative work arrangements is to give "schedule control" to employees by providing several options, including flex-time, part-time and telework. In doing so, implementation of the flex-working programs plays a key role in maintaining the balance between employees' lives and work (Julien et al., 2011).

With regard to the necessity of flex-working programs in the contemporary workforce, several studies (e.g., Moon \& Roh, 2010; Newman \& Mathews, 1999; Cayer, 2003) discuss employees' demographic changes and the increase in non-traditional types of employment in public organizations (i.e., increased numbers of employed married women due to a growing demand that women care for elders and children and employees' increased demands for work/life balance). Specifically, studies on the necessities and benefits of implementing flex-working programs are divided into two distinct discussions: for employees and employers.

From the employee viewpoint, a high level of work-family conflict (i.e., an imbalanced relationship between work and life) is more likely to have detrimental effects on employees' physical health (Madsen, 2003), as well as mental stress and dissatisfaction (Burke \& Greenglass, 1999; MacEwen \& Barling, 1994). In contrast, Newman \& Mathews (1999) discuss how a well-implemented and designed flex-working program provides employees with a high level of flexibility in terms of working conditions such as schedule, place and job type. Because of this increased flexibility, employees are likely to have positive perceptions of their work and organizations. Second, with regard to employers' potential benefits from flex-working programs, a high level of work-family balance provided by such programs is likely to improve employees' job satisfaction (Anderson, Coffey \& Byerly, 2002), organizational commitment (Thompson, Beauvais \& Lyness, 1999), and organizational performance and productivity (Pfeffer, 1994; Mumford \& Budd, 2006), as well as reduce employee turnover rates (Greenhaus, Parasuraman \& Collins, 2001).

Recently, two empirical studies (Lee \& Hong, 2011; Julien et al., 2011) examine the impacts of family-friendly policies and alternative work arrangements on employees' perceived organizational outcomes in the public sector. First, Lee \& Hong (2011) examine the relative effects of four types of family-friendly policies (e.g., child care subsides, telework, paid leave for family care, and alternative work schedules) on agency performance and employees' intentions to leave in U.S. federal agencies. The empirical findings of Lee \& Hong's (2011) research show that only satisfaction with an agency's child care subsidies has a positive impact on reducing employees' intentions to leave. The other three types of family-friendly policies do not show significant impacts on turnover rates according to Lee \& Hong's (2011) analysis. This is not consistent with previous studies on the positive effects of family-friendly policies on decreasing employee turnover rates. In addition, an employee who has a higher level of satisfaction with alternative work schedules and child care subsidies in their agency is likely to respond with a higher level of agency performance. On the contrary, an employee's satisfaction with telework shows a negative effect on agency performance (Lee \& Hong, 2011).

Second, Julien et al. (2011) primarily focus on alternative work arrangements (e.g., flex-time, compressed schedules, and telework programs) in the Canadian federal government. Specifically, they test empirical differences in employees' perceived ability to balance personal, family and work needs between employees who work flex-time, compressed schedules or telework and employees who work based on a regular work schedule (i.e., 9-5 work day, Monday-Friday work week, or on-site work). The results confirm the significant and positive relationship between employees' ability to balance work-life needs and their satisfaction with a compressed work type; however, flextime and telework do not show significant relationships with work-life balance (Julien et al., 2011). In addition, Julien et al. (2011) confirm that employees who strongly perceive that the use of alternative work arrangements is positively supported by their mangers or supervisors are more likely to report higher levels of perceived ability to balance personal, family and work needs.

Jang \& Choi (2009) discuss flex-time work and at-home or telework programs in the Korean government. Based 
on survey results for 322 government officials in 10 randomly selected central agencies, Jang \& Choi (2009) explore employees' responsiveness with respect to two flex-working programs in terms of reasons to use such programs, their positive effects, major disturbances in implementation, suggestions for positive usages or implementation, levels of satisfaction, etc. The results show that supervisors' negative attitudes toward employees' usage of flex-working programs (i.e., weak levels of managerial support for the program's implementation) are based on supervisors' concerns and expected managerial challenges in evaluating and monitoring performance for employees who participate in the flex-working programs; in addition, supervisors' negative attitudes are also based on an inflexible corporate culture in the public sector, which represents barriers to broadly implementing flex-working programs (Jang \& Choi, 2009).

\subsection{Literature on Policy Implementation Framework}

O'Toole (2000, p. 266) defines policy implementation as "what develops between the establishment of an apparent intention on the part of government to do something, or to stop doing something, and the ultimate impact in the work of action." O'Toole's (2000) definition is conceptually similar to Edwards' $(1980$, p. 1) definition of policy implementation, "the stage of policy making between the establishment of a policy... and the consequences of the policy for the people whom it effects". With an emphasis on policy actors and actions, policy implementation in the literature primarily focuses on "what emerges, or is included, as actors deal with a policy problem" (O'Toole, 2000, p. 266). In a similar vein, strategic implementation is defined as "the effort to realize in practice an organization's (or other entity's) mission, goals, and strategies, the meeting of its mandates, continued organizational learning, and the ongoing creation of public value" (Bryson, 2011, p. 27).

Discussions on policy implementation in the literature to date can be categorized into three generations of scholarship (O'Toole, 2000; Goggin, Bowman, Lester \& O’Toole, 1990). Work by Pressman \& Wildavsky (1973), considered to be the first generation of implementation study, relied completely on an in-depth single case and policy study rather than any theoretical or analytical framework. Thus, Pressman \& Wildavsky (1973) are criticized due to the weakness of their efforts to develop a scientific approach, accumulate findings or contributions or to improve the generalizability of their findings and implications.

The second generation of policy implementation study provides and develops analytical and conceptual frameworks for implementation analysis as follows (O'Toole, 2000; Goggin et al., 1990). Based on the Cuban missile crisis case, Allison $(1969 ; 1971)$ constructs three types of implementation models (e.g., rational policy, organizational process and bureaucratic politics) and specifies how each model exerts an influence differently and results in a variety of decisions, explanations and reactions to the same issue. The key contribution of Meter \& Horn (1975) to policy implementation scholarship is their identification of six factors (e.g., policy standards and objectives, policy resources, interorganizational communication and enforcement activities, characteristics of implementing agencies, economic, social and political conditions, and disposition of implementers) that influence the relationships between policy and performance. Based on these factors' influences, Meter \& Horn (1975) explore variations in determinants that account for policy performance.

Bardach (1977) emphasizes the importance of players' strategies and the rules of games that control and influence the policy implementation process. Rein \& Rabinovitz (1978) develop the model of conflict among three imperatives-legal, rational, and consensual-revealing that the extent to which conflicts among those three imperatives are resolved is an influential factor in the policy implementation process (Rein \& Rabinovitz, 1978). Elmore (1978) discusses four conceptual models (e.g., systems management, bureaucratic process, organizational development, and conflict and bargaining) which account for unsuccessful outcomes from the implementation of social programs. Nakamura \& Smallwood (1980) identify a cyclical process that is different from the classical hierarchical model of policy implementation and emphasize the influences of actors or players in policy formation, implementation, and evaluation.

To explain what types or attributes of policies are likely to be difficult to implement, Edwards (1980) suggests four variables (e.g., communication, resources, and bureaucratic structures and staff dispositions). Mazmanian \& Sabatier (1989) also specify three clusters of independent factors (e.g., tractability of the problems, ability of statute to structure implementation, and no statutory variables affecting implementation), which exert influence on the five stages of the implementation process. Finally, Elmore (1982) compares two opposite viewpoints of the implementation process: forward mapping (i.e., top-down approach) and backward mapping (i.e., bottom-up approach).

The third generation of policy implementation study (e.g., Goggin et al., 1990; Ingram \& Schneider, 1990; Glidewell \& Hargrove, 1990) primarily focuses on scientific approaches and empirical methodologies that include hypotheses testing by large- $\mathrm{N}$, quantitative analyses and an estimation of causal inferences (O'Toole, 
2000; Goggin et al., 1990).

\section{Policy Background and Process}

The part-time work program was initiated by the Korean government as a pilot program in 2002. The program permits a government employee to work less than 40 hours per week, as opposed to a full-time employee who must work 40 hours ( 5 days and 8 hours per day). Specifically, part-time employees can choose to work between 15 and 35 hours per week; however, they must work at least 3 hours per working day (Jang \& Choi, 2009; MOPAS \& MOEL, 2013).

The flex-time work program is currently the most used of the three types of flex-working programs available in Korean public organizations. The program was initiated as a pilot program at the Korean Intellectual Property Office in January 2001 and categorizes working hours into two groups of time ranges: core time (10:00-16:00) and flexible time (07:00-10:00 \& 16:00-19:00). The key rule of the flex-working program is that all employees need to work together at a core time to collaborate or communicate with other departments and civilian voices. Therefore, the program permits government employees to select among three time ranges (e.g., 8, 9 or 10:00) to begin their day, according to employees' particular needs and conditions. Because only full-time employees can apply for the flex-time work program, employees who use the program must work 8 hours per working day and 40 hours per week, and as a result, their day can end at 17, 18, or 19, depending on the employee's selection of when to start work (Jang \& Choi, 2009; MOPAS \& MOEL, 2013).

The at-home work program was initiated as a pilot program at the Korean Intellectual Property Office in March 2005. The program allows employees to work from home or any other place by utilizing mobile telecommunication technologies. Therefore, only particular tasks or positions that do not require face-to-face work with co-workers and citizens would be suitable for the program (Jang \& Choi, 2009; MOPAS \& MOEL, 2013).

Flex-working programs can be described as a human resource management strategy that can improve performance, organizational commitment and job satisfaction in the workforce by diversifying working conditions (e.g., in terms of flexible times to start and end work, work locations, and forms of employment) (Lee \& Hong, 2011; MOPAS \& MOEL, 2013). The main purposes of implementing flex-working programs in Korean government include: 1) supporting employment opportunities for married women who need to do housework or take care of babies, as well as want to continue working after the birth of a child;2) permitting employment opportunities for employees who want to engage in self-development activities (e.g., language development, taking classes, or acquisition of certifications or licenses) simultaneous with employment; 3 ) reducing employee stress and costs resulting from traffic congestion during commutes, as well as contributing to a low-carbon working environment; and 4) improving organizational and individual performance, as well as employee job satisfaction and commitment in the workforce by successfully meeting employees' diverse needs and preferences. To summarize, flex-working programs exist to maintain and support an employee's balance between work and home (or personal life) (Jang \& Choi, 2009; MOPAS \& MOEL, 2013). These purposes also identify the causal theory (i.e., relationship between input and output or outcomes) in the implementation of flex-working programs.

However, flex-working programs have both advantages and disadvantages. The expected advantages from the implementation of flex-working programs include: 1) improvements in job motivation, satisfaction, performance, and organizational commitment; 2) an achievement of work/life balance; 3) prevention against losing competent and married female employees; 4) a decrease in time, costs, mental and physical stress from commuting every day or experiencing rush hour traffic congestion; 5) an increase in opportunities for self-development and leisure activities; 6) construction of a family-friendly organizational culture in the public sector; and 7) addressing low birth rates and an aging society (Jin \& Chang, 2010; Jang \& Choi, 2009; MOPAS \& MOEL, 2013).

Flex-working programs may also have the following disadvantages: 1) difficulties and limitations in communicating and working with co-workers, especially in collaborative and long-term projects; 2) public managers' increased burdens and difficulties in managing subordinates' work progress and evaluating performance; 3 ) expected increased dissatisfaction and complaints from citizens regarding public services due to government employees' absences resulting from flex-working programs; 4) a decrease in a sense of belonging and social connectedness; and 5) difficulty in doing housework due to working at the same time (for the at-home work program) (Jin \& Chang, 2010; Jang \& Choi, 2009; MOPAS \& MOEL, 2013).

Therefore, proponents of implementing flex-working programs include current government employees (especially married women employees) who need to work, take care of children and do housework simultaneously, along with government employees who plan to do part-time and at-home work to have extra 
time for self-development and leisure activities or to reduce the time, stress and cost that results from daily commuting (Jang \& Choi, 2009; MOPAS \& MOEL, 2013). The opponents of implementing flex-working programs include public managers or supervisors whose primary responsibilities are monitoring and evaluating their subordinates' performance and work progress. In addition, citizens who need to receive public service via face-to-face meetings with government employees are also potential opponents of implementing such programs (Jang \& Choi, 2009; Jin \& Chang, 2010).

\section{Program Implementation and Analysis}

This research uses Mazmanian \& Sabatier's (1989) conceptual framework of the implementation process to address the main research question and purpose of this study. As noted earlier, Mazmanian \& Sabatier's (1989) framework for implementation analysis includes three groups of independent variables ("(1) the tractability of the problem(s) being addressed; (2) the ability of the statute to structure favorably the implementation process; and (3) the net effect of a variety of political variables on the balance of support for statutory objectives"(p. 21)) that exert an influence on the five stages of the implementation process (i.e., dependent variables: "(1) the policy outputs (decisions) of the implementing agencies; (2) the compliance of target groups with those decision; (3) the actual impacts of agency decisions; (4) the perceived impacts of those decisions; and finally (5) the political system's evaluation of a statute in terms of major revisions (or attempted revisions) in its content" (p.35)). This study primarily focuses on those three clusters of independent variables rather than the stages of the implementation process. In other words, this study explores the extent to which each of the independent variables influences the implementation of flex-working programs in South Korea's public sectors.

First, Mazmanian \& Sabatier (1989) determine whether the implementation process is successful, as well as whether the policy or statute accomplishes its objectives depends on the extent to which the problems or issues are tractable. To operationalize the tractability of problems, Mazmanian \& Sabatier (1989, p. 21-24) specify four dimensions: "(1) technical difficulties; (2) diversity of target group behavior; (3) target group as a percentage of the population; and (4) extent of behavioral change required." Based on the arguments for each of the four dimensions of the tractability of the problems, Mazmanian \& Sabatier (1989) propose that problems are more likely to be tractable if a) there is a valid causal theory between behavioral change and the problem solution, as well as more inexpensive indicators to measure performance; b) there is less diversity in behavior as a cause of the problem; c) there is more identifiable and fewer number of targets in the group; and d) there is less behavioral change required by the policy or statute.

The problems and issues in the Korean public workforces identified earlier that necessitate implementation of flex-working programs are less tractable and more difficult to address in a short period of time. Flex-working programs have been formulated and implemented since 2010 in Korean public organizations to address the following problems and strategic issues: how to resolve work-family (or life) conflict; how to provide support for women's work/family balance to address the increased rate of women with careers; how to increase the proportion of female employees in high-ranking public sector positions; and how to respond to employees' increased demands for more flexible time to pursue self-development activities.

The relationships and connections between these problems are very complicated, and a particular behavioral change or potential solution will not simply resolve a particular problem or issue because these problems stem from various factors (e.g., social, political and economic). In other words, there is less valid causation between behavioral change and the problem solution. Furthermore, it is also problematic to construct inexpensive and feasible indicators to measure the improvement of an employee's work/life balance. In a similar vein, there is significant variation among sometimes unobservable or unpredictable factors that cause these issues in Korean public organizations.

The target group of flex-working programs is diversified and may include numerous government employees. Because each of the flex-working programs (e.g., flex-time, part-time, and at-home work) has different contents and objectives and requires somewhat different managerial roles, the size of the target group of flex-working programs includes a considerable number of government employees. In addition, it is not easy to identify the exact target group for each of the flex-working programs because an employee's decision to use each type of flex-working programs can change frequently depending on changes in her/his demographic factors or family composition. Furthermore, supervisors, mangers or co-workers may change behavior based on their tasks, responsibilities and managerial roles, which can be influenced by their subordinates or co-workers who use the flex-working programs. In summary, based on Mazmanian \& Sabatier's (1989) conceptual framework on the tractability of problems, the problems surrounding the flex-working programs in the Korean public workforce are less tractable. 
Second, Mazmanian \& Sabatier (1989) propose that the ability of policy decisions or statutes to structure the implementation process influences on the degree to which the policy implementation and its process succeed in achieving the intended objectives and outcomes. Specifically, Mazmanian \& Sabatier (1989, p. 25-30) provide seven dimensions of factors to identify the extent to which a policy decision or statute has the ability to structure implementation: "(1) clear and consistent objectives, (2) incorporation of adequate causal theory, (3) initial allocation of financial resources, (4) hierarchical integration within and among implementing institutions, (5) decision rules of implementing agencies, (6) recruitment of implementing agencies, (7) formal access by outsiders".

Mazmanian \& Sabatier (1989) propose that the implementation process is more likely to achieve its objectives and outcomes successfully if a policy decision or statue includes more clear and precise objectives; if it identifies a valid causal theory; if it provides financial resources to implement the policy; if it has hierarchical controls for implementing agencies; if it includes strict rules for decision-making by implementing agencies for achieving goals and outcomes; if an implementing agency and its officials are strongly committed to attaining the objectives of a policy decision or statue; and if outside actors' participation and voices positively support policy objectives.

As discussed earlier, the policy document on the flex-working programs proposed by the Ministry of Public Administration and Security (MOPAS) and the Ministry of Employment and Labor (MOEL) does not identify specific ranked goals or the short-term objectives expected from the implementation of the flex-working programs in Korea's public sectors. On the contrary, it repeatedly stresses that implementing flex-working programs plays a role in improving an employee's organizational commitment, performance, and satisfaction with his/her job and organization, as well as contributing to an employee's work/family (life) balance by providing more flexible work schedules, job types and places. In other words, the MOPAS and MOEL do not successfully identify clear causal relations among inputs, outputs or short-and long-term objectives relevant to the implementation of flex-working programs by implementing agencies.

Generally, the intergovernmental relationships among central, provincial, and local governments in Korea approximate hierarchical structures rather than horizontal relationships (i.e., the central government usually has more decision-making power and controlling authority for provincial and local governments' policies and strategic plans). Nevertheless, these two central agencies (e.g., MOPAS \& MOEL) do not positively exert their hierarchical leadership and authority as policy designers or initiators, nor do they clarify rigorous rules for the officials in agencies to use in successfully implementing flex-working programs to address the problems and challenges faced by Korea's public sector workforces. MOPAS and MOEL do not show a strong desire for the implementation of flex-working programs, but rather allow public organizations to implement the programs autonomously. In the case of the implementation of flex-working programs, the factors regarding the provision of financial resources and outside policy actors' participation and activity in the process are not directly relevant.

Third, Mazmanian \& Sabatier (1989) argue that no statutory factors also have significant roles in influencing on the implementation process and the achievement of policy objectives or outcomes with regard to the other two independent variables discussed so far (e.g., tractability of the problems and the ability of a statute or policy decision to structure implementation). The extent to which the policy implementation successfully attains its objectives depends on the "interaction between legal structure and political process" (Mazmanian \& Sabatier, 1989, p. 30). To explain what types of no statutory variables influence the implementation process, Mazmanian \& Sabatier (1989, p. 30-35) suggest five variables as follows: "(1) socioeconomic conditions and technology, (2) public support, (3) attitudes and resources of constituency groups, (4) support from sovereigns, and (5) commitment and leadership skill of implementing officials".

Specifically, Mazmanian \& Sabatier (1989) suggest that the success of the policy implementation process and the attainment of its policy or statutory objectives are likely to be influenced by the following: changes in social, economic, political and technological conditions regarding the objectives and necessities of a statute or policy; the degree of public support and the formation of public opinion regarding the policy decision and its implementation; changes in the resources and interests of relevant constituents over time during the implementation process; the extent to which leaders of the implementing agencies support the policy implementation and perceive its objectives as important; and finally, the level of leadership skill and commitment among agency officials in attaining policy goals.

Among these five no statutory factors, the fifth variable, the degree of implementing officials' commitment, managerial capacity and leadership skills, is highly relevant to the implementation of flex-working programs in Korea's public. Based on Mazmanian \& Sabatier's (1989, p. 34) discussion, the commitment of agency officials 
to accomplish policy goals is composed of two dimensions-"the direction and ranking of those objectives in officials' priorities" and "officials' skill in realizing those priorities". Thus, it appears that agency officials in Korea's public organizations are not committed to realizing employees' work/family balance through the implementation of the flex-working programs and they do not appear to perceive the importance of flex-working program implementation as a high priority.

Furthermore, officials have negative perceptions regarding the implementation of flex-working programs in their agencies due to the following concerns: increased challenges in managing and monitoring the performance of their subordinates who use the flex-working programs; obstacles and limitations on communication, cooperation, and mutual relationships with subordinates and among employees; and increased citizens' complaints and inconvenience due to employees' frequent absence under the flex-working programs (Jin \& Chang, 2010; Jang \& Choi, 2009).

As discussed earlier, several benefits and advantages expected from implementing flex-working programs (e.g., improvement of organizational performance, commitment, and job satisfaction) can be considered from the employer's perspective. In addition, from an employee's viewpoint, work/family (life) balance can be improved by using the flex-working programs. However, these types of benefits seem to be considered by agency officials as very abstract with regard to long-term outcomes rather than providing short-term objectives and valid causal relations. Therefore, officials in implementing agencies are less likely to rank the implementation of flex-working programs among their priorities and are more likely to consider the expected and increased burdens and managerial challenges resulting from their subordinates' usage of flex-working programs.

\section{Evaluation Methods}

The flex-working programs are being implemented in South Korea's public organizations (i.e., on-going programs). Therefore, it is not easy to evaluate at the current stage whether the implementation of flex-working programs has been successful or whether implementation has attained the objectives and outcomes intended at the policy formulation stage by using particular indicators or criteria. Nevertheless, to contribute to the development of evaluation standards, this study suggests potential evaluation methods for the implementation of flex-working programs according to three viewpoints (e.g., employees' outcomes, employers' outcomes and the implementation process) as follows.

First, from an employee's perspective, the perceived extent to which participation in the flex-working programs reduces an employee's work/family conflict, as well as improves his/her ability to balance between work and family (life) should be considered as evaluation criteria. Second, according to the employer's perspective, an employer's perceived degree to which the implementation of flex-working programs and his/her employee's usage of the programs improves performance, job satisfaction, organizational commitment and reduces turnover rates might be applicable for measuring the outcomes of the flex-working programs. Third, both the employer and employee's perceived satisfaction with the extent to which the flex-working program designs include specific contents, guidelines, training, and education opportunities to promote understanding of the program, as well as the policy inputs such as budget and human resources that are assigned for the success of the implementation of flex-working programs can be potential indicators to measure the success or failure of the implementation process. All measures are perceived, subjective indicators from the employees' perspective in the public workforce with regard to outcomes from the implementation of the flex-working programs and the implementation process itself.

\section{Conclusion}

The main purpose of this research is to examine what factors negatively influence the implementation of flex-working programs (e.g., flex-time, part-time and at-home work) such that only 1.6 percent of government officials on average used one of these programs in 2011. Based on analysis of Mazmanian \& Sabatier's (1989) conceptual framework of the implementation process, this study confirms that the problems and issues in Korean's public workforce that were expected to be resolved by the implementation of the flex-working programs are less tractable and not easily achieved in the short term. In addition, the flex-working program design does not include valid causal theory between behavioral change and the problem solution and contains a very broad level of target groups of government employees. The flex-working program policy document does not provide clear and valid causal relations among inputs, outputs or short-and long-term goals for employees, managers or supervisors in implementing agencies. Furthermore, as policy designers or makers, the two central government agencies (MOPAS \& MOEL) have not exercised the hierarchical power, authority or rules necessary for a successful implementation process and outcomes with regard to public officials in government agencies. 
Finally, public managers display very low levels of commitment and managerial capacity to positively implement flex-working programs as a priority.

To successfully implement flex-working programs in Korea's public sector and to attain their primary policy goal of improving an employee's work/life balance, this study concludes with the following suggestions. First, it is necessary that public mangers change their negative attitudes regarding their employees' participation in flex-working programs into positive perceptions of the impacts of the programs on employees' work/life balance, improvement of organizational outcomes, and the construction of sustainable work environments among the public workforces. To do so, it is also necessary that the current flex-working program policy identify specific effects, requirements or procedures, encourage behavior changes by both employees and employers, develop ways to resolve implementation problems and strategies to target particular groups of employees' for participation in the implementation of flex-working programs. Finally, to implement the programs successfully, institutional support such as job sharing, a proper division of tasks, a performance-based organizational culture, and the development of jobs that are suitable for the flex-working programs are necessary in public agencies.

\section{Acknowledgements}

The author gratefully acknowledges helpful comments and suggestions from anonymous referees. In addition, my special appreciation goes to Dr. Lorenda A. Naylor for her guidance and comments as well as to my life-time supporter, Mi Jang.

\section{References}

Allison, G. T. (1969). Conceptual Models and the Cuban Missile Crisis. American Political Science Review, 63(3), 689-718. http://dx.doi.org/10.2307/1954423

Allison, G. T. (1971). Essence of Decision: Explaining the Cuban Missile Crisis. Boston, MA: Little Brown.

Anderson, S., Coffey, B., \& Byerly, R. (2002). Formal Organizational Initiatives and Informal Workplace Practices: Links to Work-Family Conflict and Job Related Outcomes. Journal of Management, 28, 787-810.

Bardach, E. (1977). The Implementation Game: What Happens After a Bill Becomes a Law. Cambridge, MA: MIT Press.

Bryson, J. M. (2011). Strategic Planning for Public and Nonprofit Organizations: A Guide to Strengthening and Sustaining Organizational Achievement (4th ed.). San Francisco, CA: Jossey-Bass A Wiley Imprint.

Burke, R., \& Greenglass, E. (1999). Work-Family Conflict, Spouse Support and Nursing Staff Well-Being during Organizational Restructuring. Journal of Occupational Health Psychology, 4, 327-336. http://dx.doi.org/10.1037/1076-8998.4.4.327

Cayer, N. J. (2003). Public Employee Benefits and the Changing Nature of the Workforce. In S. W. Hays \& R. C. Kearney (Eds.), Public Personnel Administration: Problems and Prospects (pp.167-179). Upper Saddle River, NJ: Prentice Hall.

Edwards, G. C. (1980). Implementing Public Policy. Washington, DC: Congressional Quarterly Press.

Elmore, R. F. (1978). Organizational Models of Social Program Implementation. Public Policy, 26(2), 186-228.

Glidewell, J. C., \& Hargrove, E. C. (n. d.). Dimensions of Impossibility. In E. C. Hargrove \& G. C. J. Glidewell (Eds.), Impossible Jobs in Public Management (pp.3-27). Lawrence, KA: University Press of Kansas, 1990.

Goggin, M. L., Bowman, A. O’M., Lester, J. P., \& O’Toole, L. J. (1990). Implementation Theory and Practice: Toward a Third Generation. New York: HarperCollins Publishers.

Greenhaus, J., Parasuraman, S., \& Collins, K. (2001). Career Involvement and Family Involvement as Moderators of Relationships between Work-Family Conflict and Withdrawal from a Profession. Journal of Occupational Health and Psychology, 6(2), 91-100. http://dx.doi.org/10.1037/1076-8998.6.2.91

Ingram, H., \& Schneider, A. (1990). Improving Implementation through Framing Smarter Statutes. Journal of Public Policy, 10, 67-88. http://dx.doi.org/10.1017/S0143814X00004682

Jang, H., \& Choi, M. (2009). Evaluation on Roh Moo-Hyun Administration's Family-Friendly Working Policy: Study on Government Employees' Perceptions on Teleworking and Flex-time Work. Korean Public Personnel Administration Review, 8(3), 121-154.

Jin, J., \& Chang, Y. (2010). A Study on Development of Flex-working Program in Public Sector. Korean Public Personnel Administration Review, 9(3), 29-55.

Julien, M., Somerville, K., \& Culp, N. (2011). Going Beyond the Work Arrangement: The Crucial Role of Supervisor Support. Public Administration Quarterly, 35(2), 167-205.

Kingdon, J. W. (2003). Agendas, Alternatives, and Public Policies. New York, NY: Addison-Wesley Educational 
Publishers

Lee, S. Y., \& Hong, J. H. (2011). Does Family-Friendly Policy Matter? Testing Its Impact on Turnover and $\begin{array}{lllll}\text { Performance. } & \text { Public } & \text { Administration } & \text { Review, } & 71(6),\end{array}$ http://dx.doi.org/10.1111/j.1540-6210.2011.02416.x

MacEwen, K., \& Barling, J. (1994). Daily Consequences of Work Interference with Family and Family Interference with Work. Work and Stress, 8, 244-254. http://dx.doi.org/10.1080/02678379408259996

Madsen, S. (2003). The Effects of Home-Based Teleworking on Work-Family Conflict. Human Resource Development Quarterly, 14, 35-58. http://dx.doi.org/10.1002/hrdq.1049

Mazmanian, D. A., \& Sabatier, P. A. (1989). Implementation and Public Policy with a New Postscript. Lanham, MD: University Press of America.

Moon, S. Y., \& Roh, J. (2010). Balancing Work and Family in South Korea's Public Organizations: Focusing on Family-Friendly Policies in Elementary School Organizations. Public Personnel Management, 39(2), 117-131.

Mumford, K. A., \& Budd, J. W. (2006). Family-Friendly Workplace Practices in Britain: Availability and Perceived Accessibility. Human Resource Management, 45(1), 91-110.

Nakamura, R. T., \& Smallwood, F. (1980). The Politics of Policy Implementation. New York: St. Martin's Press.

Newman, M., \& Mathews, K. (1999). Federal Family-Friendly Workplace Policies: Barriers to Effective Implementation. Review of Public Personnel Administration, 19(3), 34-48. http://dx.doi.org/10.1177/0734371X9901900303

O’Toole, L. J. (1989). Alternative Mechanisms for Multiorganizational Implementation: The Case of Wastewater Management. Administration and Society, 21(3), 313-339. http://dx.doi.org/10.1177/009539978902100302

O'Toole, L. J. (2000). Research on Policy Implementation: Assessment and Prospects. Journal of Public $\begin{array}{llll}\text { Administration } \quad \text { Research } & \text { Theory, }\end{array}$ http://dx.doi.org/10.1093/oxfordjournals.jpart.a024270

Pfeffer, J. (1994). Competitive Advantage through People: Unleashing the Power of the Work Force. Boston, MA: Harvard Business School Press.

Pressman, J. L., \& Wildavsky, A. (1973). Implementation. Berkeley, CA: University of California Press.

Rein, M., \& Rabinovitz, F. F. (1978). Implementation: A Theoretical Perspective. In W. D. Burnham \& M. W. Weinberg (Eds.), American Politics and Public Policy (pp. 307-335). Cambridge, MA: Massachusetts Institute of Technology Press.

Sabatier, P. A. (1986). Top-Down and Bottom-Up Approaches to Implementation Research: A Critical Analysis and Suggested Synthesis. Journal of Public Policy, 6, 21-48. http://dx.doi.org/10.1017/S0143814X00003846

The Ministry of Employment and Labor (MOEL). (n. d.). Retrieved July 6, 2013, from http://www.moel.go.kr

The Ministry of Health and Welfare (MOHW). (n. d.). Retrieved July 6, 2013, from http://www.mw.go.kr/front/index.jsp

The Ministry of Public Administration and Security (MOPAS). (n. d.). Retrieved July 6, 2013, from $\mathrm{http} / /$ www.mopas.go.kr/gpms/ns/mogaha/user/nolayout/main/nationDisplay.action

Thompson, C., Beauvais, L., \& Lyness, K. (1999). When Work-Family Benefits Are Not Enough: The Influence of Work-Family Culture on Benefit Utilization, Organizational Attachment and Work-Family Conflict. Journal of Vocational Behavior, 54, 392-415. http://dx.doi.org/10.1006/jvbe.1998.1681

Van Meter, D. S., \& Van Horn, C. E. (1975). The Policy Implementation Process: A Conceptual Framework. Administration and Society, 6, 445-488. http://dx.doi.org/10.1177/009539977500600404

\section{Copyrights}

Copyright for this article is retained by the author(s), with first publication rights granted to the journal.

This is an open-access article distributed under the terms and conditions of the Creative Commons Attribution license (http://creativecommons.org/licenses/by/3.0/). 